\title{
Molecular detection of $E$. granulosus sheep strain (G1) infections in naturally infected dogs in Punjab (India)
}

\author{
B. B. SINGH*, R. SHARMA, J. K. SHARMA, J. P. SINGH GILL
}

\author{
${ }^{1}$ School of Public Health \& Zoonoses, Guru Angad Dev Veterinary \& Animal Sciences University, Ludhiana -141004, \\ Punjab (India), "E-mail: bbsdhaliwal@gmail.com
}

\begin{abstract}
Summary
Echinococcosis is a preventable but neglected zoonosis in India. Although the disease in domestic animals is usually asymptomatic, huge economic losses have been reported due to cystic echinococcosis in livestock in India. The molecular characterization of Echinococcus from dog populations has not been previously carried out in Punjab (India). A total of 237 pet and stray dog faecal samples were collected and examined for the presence of eggs of the Taeniidae family in Punjab (India). A 255 base pair fragment of the mitochondrial 12S rRNA gene was amplified and the presence of sheep strain (G1) of E. granulosus has been reported. We detected eggs of the Taeniidae family in 2.11 per cent of the faecal samples. High prevalence was recorded in stray dogs $(9.52 \%)$ living near slaughter shops/post mortem areas. The prevalence of $E$. granulosus sheep strain (G1) using PCR was found to be 0.84 per cent in naturally infected dogs. This is the first study confirming the presence of E. granulosus (G1) sheep strain in dogs in Punjab (India).

The results reveal the presence of sheep strain of E. granulosus and demand implementation of Animal Birth Control programme so as to control the stray dog population of the country.
\end{abstract}

Keywords: Echinococcus granulosus; dogs; sheep strain (G1); PCR; North India

\section{Introduction}

The disease echinococcosis is caused by the adult or the larval stages of cestodes belonging to the genus Echinococcus (Family Taeniidae). Dogs become infected with the parasite by ingesting protoscoleces found in fertile hydatid cysts of suitable intermediate hosts (Gemmell et al., 1986). The dog's role as a definitive host for E. granulosus echinococcosis has been widely studied and recognized as being a significant public health problem worldwide. Most pet dogs are considered an integral part of the owners' family and are treated accordingly (Traub, 2003). The sheep strain (G1) of E. granulosus has been found to be associated with most human infections across the globe (Thompson \& McManus, 2002; Snabel et al., 2009; Santivanez et al., 2008).

E. granulosus echinococcosis is an important public health and food safety issue in many developing countries. In India, uncontrolled population of stray and semi-domesticated dogs, free access of dogs to slaughter waste of food animals, presence of open/fallen carcasses and lack of meat inspection undoubtedly perpetuate the transmission cycle (Dutta, 2002; Singh et al., 2012). There is an estimated 19.2 million stray dogs in the country and this population is believed to be rising (WHO, 1996). However, a portion of dogs classified as "strays" in India are in fact semi-domesticated dogs belonging to street dwellers in urban areas and more frequently, farming communities in rural areas (Traub, 2003). Poor hygiene, overcrowding, lack of veterinary attention and zoonotic awareness in developing countries such as India further exacerbates the risks of transmission of disease (Schantz, 1991; Singh et al., 2011).

In India, the hydatid cysts are found in most of the food producing animals (cattle, buffalo, sheep, goat and pigs) and humans; the disease in intermediate hosts occurs throughout the country at varying rates (Singh et al., 2010; 2012; Pednekar et al., 2009). The significant increase $(\mathrm{p}<0.001)$ in sero positivity during a five year period $(23.12 \%, 1999-$ $2003)$ as compared with previous years $(10.97 \%, 1984-$ 1998), and a similar increase $(\mathrm{p}<0.001)$ in positive Casoni's test $(33.83 \%, 1999-2003$ versus $21.38 \%, 1984-1998)$ has been reported for human cystic echinococcosis in northern India (Khurana et al., 2007). High seroprevalence of human hydatidosis has also been reported in certain occupational groups in northern India (Singh et al., 2013). In a recent study, E. granulosus G3 (53.1\%) and G1 (40.62\%) genotypes were associated with most of CE (30/32) human cases in northern India (Sharma et al., 2013). 
Despite the strong impact and the endemicity of this serious zoonosis, molecular characterization of Echinococcus from dog populations has not been carried out in Punjab (India). The recognition of strain variation can prove beneficial for the implementation of disease prevention and control programmes particularly in endemic countries such as India.

\section{Materials and methods}

\section{Animals, Study area and Sample collection}

Faecal samples from 237 dogs, including 109 pet dogs visiting small animal clinics, 86 stray dogs catched by Dogy Lane Veterinary Hospital from residential areas in Ludhiana (Punjab) and 42 stray dogs having access to condemned meat/offals residing near slaughter shops/post mortem areas in district Ludhiana were collected. The complete history, wherever possible, of each dog was recorded in specific performa. The faecal samples were collected aseptically in stool collection bottles. Samples were examined fresh and were also preserved separately in 5 per cent formal saline ( 1 part faeces: 4 parts formal saline) for microscopic analysis. This was performed within 4 hours of collection of the samples.

\section{Detection of Taeniidae family (Echinococcus) eggs in faecal samples}

The taeniid eggs were detected as previously described (Ito, 1980; Theinpont et al., 1979; OIE, 2008). Briefly, 2 gram of faecal sample were mixed in water in $10-15 \mathrm{ml}$ test tube and centrifuged at $1000 \mathrm{~g}$ for 10 minutes. The sediment was mixed with sucrose solution (Sp. gr. 1.27) and again centrifuged at $1000 \mathrm{~g}$ for 10 minutes. The test tube was filled to the top and the cover glass was placed on it. The cover glass was examined microscopically after 12 hours. All Taenia egg-positive faecal samples were stored at $-20{ }^{\circ} \mathrm{C}$. The personnel engaged in echinococcosis survey wore appropriate protective clothing and took all the other necessary precautions as described (WHO \& OIE, 2001). Faeces were rendered safe in the field by being packed in secure leak-proof containers for transport and later decontaminated. Additionally, eggs of any other parasitic species if found were also recorded.
DNA Extraction and E. granulosus PCR

The fluid (about $300 \mu \mathrm{l}$ ) containing eggs after coprological examination were used for the extraction of the DNA. DNA extraction was carried out using the Hi PurA spin stool Kit (Himedia) as per the manufacturer's instructions. The eluted DNA was kept at $-20{ }^{\circ} \mathrm{C}$ till further use. A 255 base pair fragment of the mitochondrial $12 \mathrm{~S}$ rRNA gene was amplified from each isolate using the previously published primer pairs: forward primer Eg 1 F' CATTAATGTATTTTGTAA AGTTG, reverse primer Eg 2 R' CACATCATCTTACAAT AACACC (Stefanic et al., 2004). PCR was performed using DNA extracted from taeniid eggs as described above. The incubation was carried out in Master cycler Pro (Eppendorf, T-Gradient) thermal cycler. The PCR conditions were optimized using different temperature setups for annealing and concentrations of reagents/ chemicals with slight modifications as per the method of Stefanic et al. (2004). Final volume of reaction mixture was adjusted to $25 \mu \mathrm{l}$ with DEPC treated water/ autoclaved distilled water. DNA template used was $1-5 \mu \mathrm{l}(10-200 \mathrm{ng})$. DNA from the hydatid cyst of the sheep strain (G1) of E. granulosus was included as positive control.

For PCR, the reaction mixture consisted of Taq polymerase $2.0 \mathrm{U}$, PCR buffer $1 \mathrm{X}, \mathrm{MgCl}_{2} 2.5 \mathrm{mM}$, dNTP's $200 \mu \mathrm{M}$ of each and 20 pmol of each primer. The thermal cycling conditions were as follows: $95^{\circ} \mathrm{C}$ for $5 \mathrm{~min} ; 40$ cycles of $94{ }^{\circ} \mathrm{C}$ for $30 \mathrm{sec}, 53.5^{\circ} \mathrm{C}$ for $30 \mathrm{sec}$, and $72{ }^{\circ} \mathrm{C}$ for $45 \mathrm{sec}$ and a final extension at $72^{\circ} \mathrm{C}$ for $10 \mathrm{~min}$ (Stefanic et al., 2004). The PCR recommended by Stefanic et al. (2004) was performed with slight modifications. The uracil DNA glycosylase were not included and standard dTTP was used instead of the recommended dUTP (Boufana et al., 2008). This PCR is specific for E. granulosus 'sheep strain' and yield a 255 bp amplification product. The PCR amplified products were analyzed on $1.5 \%$ agarose gel stained with ethidium bromide $(0.5 \mu \mathrm{g} / \mathrm{ml})$ at $70 \mathrm{~V}(45-55$ minutes $)$.

\section{Relative risk}

The relative risk (RR) was calculated as: Relative Risk = Probability (Number of stray dogs infected and having access to condemned meat and offals/number of stray dogs examined having access to condemned meat and offals) divided by Probability (Number of stray dogs infected and

Table 1. Prevalence of parasitic species eggs in faecal samples of pet and stray dogs in Punjab (India)

\begin{tabular}{|c|c|c|c|c|c|}
\hline \multirow[b]{2}{*}{$\begin{array}{l}\text { S. } \\
\text { No. }\end{array}$} & \multirow[b]{2}{*}{ Category of dogs } & \multirow[b]{2}{*}{$\begin{array}{c}\text { No. of samples } \\
\text { examined }\end{array}$} & \multicolumn{3}{|c|}{ No. of samples positive } \\
\hline & & & $\begin{array}{c}\text { Taeniid } \\
\text { eggs }\end{array}$ & $\begin{array}{l}\text { Toxocara } \\
\text { eggs }\end{array}$ & $\begin{array}{c}\text { Strongyle } \\
\text { eggs/Strongyloid } \\
\text { larvae }\end{array}$ \\
\hline 1 & Pet dogs & 109 & 0 & 2 & 0 \\
\hline 2 & Stray dogs living in residential colonies & 86 & 1 & 0 & 7 \\
\hline 3 & $\begin{array}{l}\text { Stray dogs having access to condemned } \\
\text { meat/offal's (living near slaughter } \\
\text { shops/post mortem areas) }\end{array}$ & 42 & 4 & 0 & 0 \\
\hline & Total & 237 & 5 & 2 & 7 \\
\hline
\end{tabular}




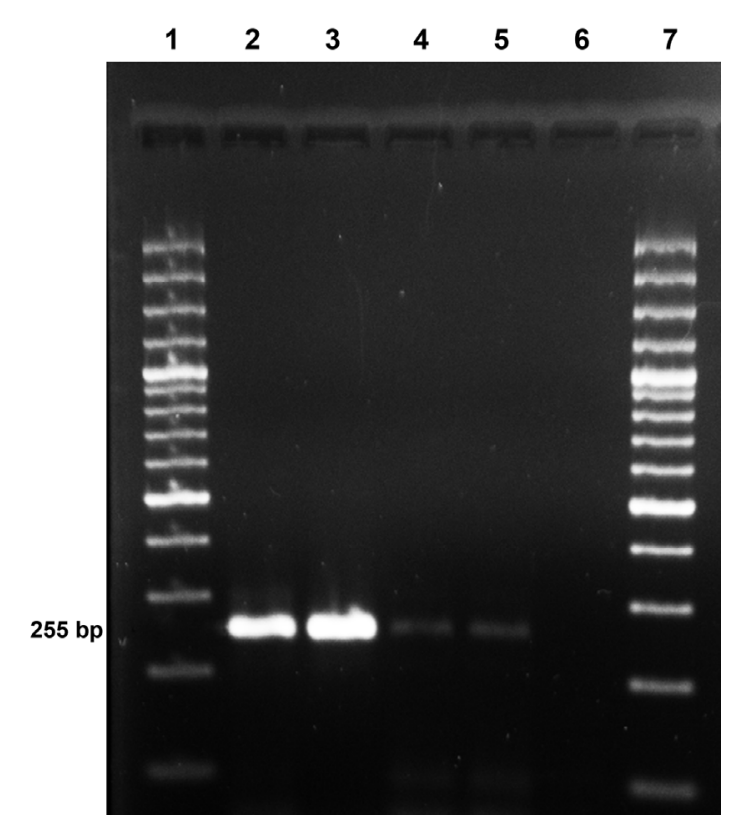

Fig. 1. E. granulosus PCR of $12 \mathrm{~S}$ rRNA gene from taeniid eggs. From left to right: 1 and 7 DNA marker, 2 and 3 positive control (in duplicate), 4 and 5 positive samples and 6 negative control, respectively

not having access to condemned meat and offals/number of stray dogs examined and not having access to condemned meat and offals).

\section{Results}

Out of a total of 237 dogs examined, 5 were positive for eggs of the Taeniidae family with overall prevalence rate of 2.11 per cent (Table 1). The prevalence of the eggs was highest in stray dogs $(9.52 \%)$ having access to condemned meat/offal's (living near slaughter shops/post mortem areas) followed by stray dogs catched by Doggy Lane Veterinary Hospital $(1.16 \%)$ from residential areas in Ludhiana (Punjab). None of the sample was found positive from 109 pet dogs visiting small animal clinic GADVASU. The relative risk for the presence of Taeniidae family eggs was found to be 8.19 (95\% CI 0.94 - 71.0) times high $(\mathrm{P}=0.056)$ in stray dogs having access to condemned meat/offal's (living near slaughter shops/post mortem areas) than the stray dogs living in other residential areas. Two of the five egg containing samples were found positive using PCR indicating 0.84 per cent prevalence of sheep strain (G1) of E. granulosus in this study (Fig. 1). Additionally, Toxocara eggs and strongyle eggs/strongyloid larvae were also detected in 2 pet and 7 stray dog faecal samples, respectively (Table 1).

\section{Discussion}

This is the first study revealing the presence of sheep strain (G1) of E. granulosus among naturally infected dogs in Punjab state of northern India. There are alarming indications of increasing human health risks associated with echinococcosis (WHO \& OIE, 2001). E. granulosus in dogs has also been reported from southern India (Prathiush et al., 2008; Singh et al., 2010). A total of 368 faecal supernatants were tested and 16 samples were found to be positive for $E$. granulosus echinococcosis in dogs using sandwich ELISA in Karanatka state of southern India (Prathiush et al., 2008). In another study, prevalence of E. granulosus in stray dogs living near abattoirs was found to 17.02, 27.77 and 18.18 percent respectively in Assam, Meghalaya and Mizoram states located in Eastern India (Deka et al., 2008).

E. granulosus echinococcosis occurs across the globe. A PCR assay to investigate 131 purged dogs was carried out in Kazakhstan: eighteen dogs harboured Echinococcus worms, coproantigen detection was positive in 15 , taeniid eggs could be recovered from 13 and eight of the egg containing samples were positive in the PCR for E. granulosus (Stefanic et al., 2004). In Hejing County (Xinjiang), 17 out of 30 necropsied dogs examined were found infected with sheep strain (G1) of E. granulosus (Zhang et al., 2006).

In the present study, prevalence of E. granulosus among naturally infected dogs is likely to be underestimated, as the application of techniques such as arecoline purgation and examination of necropsied dogs are likely to be more sensitive for detecting E. granulosus infections in dogs (Lahmar et al., 2007). Moreover, presence of other strains of E. granulosus could not be ruled out in the present study. High prevalence of taeniid eggs in stray dogs $(9.52 \%)$ living near slaughter shops/post mortem areas indicate that uninspected meat and illegal slaughter serve as important source of contamination in dogs. The problems such as lack of biomedical waste or carcass disposal facilities at these establishments needs attention and must be addressed.

\section{Conclusions}

The results indicate that E. granulosus sheep strain is circulating among canine and livestock species and is a serious public health issue in Punjab state of Northern India. Sound science based strategies must be formulated for prevention and control of this serious zoonosis.

\section{Conflict of interest statement}

No financial or personal relationships between the authors and other people or organizations have inappropriately influenced (bias) this work.

\section{Acknowledgements}

This study was financially supported by School of Public Health \& Zoonoses, Guru Angad Dev Veterinary \& Animal Sciences University, Ludhiana, Punjab, India.

\section{References}

Boufana, B. S., CAmpos-Ponce, M., NAIDICh, A., Buishi, I., Lahmar, S., Zeyhle, E., Jenkins, D. J., Combes, B., Wen, H., XiaO, N., NakaO, M., Ito, A., QIU, J., Craig, P. S. (2008): Evaluation of three PCR assays for the identifi- 
cation of the Sheep strain (Genotype 1) of Echinococcus granulosus in canid feces and parasite tissues. Am. J. Trop. Med. Hyg., 78(5): $777-783$

Deka, D. K., Islam, S., Borkakoty, M., SAleque, A., Hussain, I., NATH, K. (2008): Prevalence of Echinococcus granulosus in dogs and hydatidosis in herbivores of certain North Eastern states of India. J. Vet. Parasitol., 22 (1): $27-30$

Dembicki, D., Anderson, J. (1996): Pet Ownership may be a factor in improved health of the elderly. J. Nutr. Elder., 15: 15 - 31. DOI: 10.1300/J052v15n03_02

DuTTA, J. K. (2002): Disastrous results of indigenous methods of rabies prevention in developing countries. Int. J. Infect. Dis., 6: 236 - 237

FriedmanN, E., Thomas, S.A. (1995): Pet ownership, social support and one year survival after acute myocardial infarction in the Cardic Arrtythmia Suppression Trial (CAST). Amer. J. Cardiol., 76: 1213 - 1217. DOI: 10.1016/S0002-9149(99)80343-9

Gemmell, M. A., LAWson, J. R., Roberts, M. G. (1986): Population dynamics in echinococcosis and cysticercosis: biological parameters of Echinococcus granulosus in dogs and sheep. Parasitology, 92(3): $599-620$

ITO, S. (1980): Modified Wisconsin sugar centrifugalfloatation technique for nematode eggs in bovine faeces. $J$. Jap. Vet. Med. Assoc., 33: $424-429$

Khurana, S., Das, A., Malla, N. (2007): Increasing trends in seroprevalence of human hydatidosis in North India: a hospital-based study. Trop. Doct., 37(2): 100 - 102 LAhmar, S., Boufana, B., Bradshaw, H., Craig, P.S. (2007): Screening for Echinococcus granulosus in dogs: Comparison between arecoline purgation, coproELISA and coproPCR with necropsy in pre-patent infections. Vet. Parasitol., 144 (3 - 4): 287 - 292. DOI: 10.1016/ j.vetpar.2006.10.016

Pednekar, R. P., Gatne, M. L., Thompson, R. C. A.,TRAUB, R. J (2009): Molecular and morphological characterisation of Echinococcus from food producing animals in India. Vet. Parasitol., $165(1-2)$ : 58 - 65. DOI: 10.1016/j.vetpar.2009.06.021

Prathiush, P. R., D'souza, P. E., Javaregowda, A. K. (2008): Diagnosis of Echinococcus granulosus infection in dogs by a coproantigen sandwich ELISA. Vet. Arh., 78 (4): $297-305$

Santivañez, S. J., Gutierrez, A. M., RosenzVit, M. C., Muzulin, P. M., Rodriguez, M. L., Vasquez, J. C., Rodriguez, S., Gonzalez, A. E., Gilman, R. H., Garcia, H. H., The Cysticercosis Working Group In PerU (2008): Human hydatid disease in Peru is basically restricted to Echinococcus granulosus genotype G1. Am. J. Trop. Med. Hyg., 79(1): $89-92$

SchANTZ, P. (1991): Parasitic zoonoses in perspective. Int. J. Parasitol., 21: 161 - 170. DOI: 10.1016/0020-7519(91) 90006-S

Sharma, M., Sehgal, R., Fomda, B. A., Malhotra, A., MALLA, N. (2013): Molecular characterization of Echino- coccus granulosus cysts in North Indian patients: Identification of G1, G3, G5 and G6 genotypes. PLoS. Negl. Trop. Dis., 7(6): e2262. DOI: 10.1371/journal.pntd.0002262.

Singh, B. B., Sharma, J. K., Ghatak, S., Sharma, R., BAL, M. S., TUli, A., GILl, J. P. S. (2012): Molecular epidemiology of echinococcosis from food producing animals in North India. Vet. Parasitol., 186(3 - 4), 503 - 506. DOI: 10.1016/j.vetpar.2011.11.064

Singh, B. B., Sharma, R., Sharma, J. K., Juyal, P. D. (2010): Parasitic zoonoses in India- an overview. Rev. sci. tech. Off. Int. Epizoot., 29 (3): 629 - 637

Singh, B. B., Sharma, R., Gill, J. P. S., Aulakh, R. S., BANGA, H. S. (2011): Climate change, Zoonoses and India. Rev. sci. tech. Off. Int. Epizoot., 30 (3): 779 - 788

Singh, B. B., Singh, G., Sharma, J. K., AulaKh, R. S., GILL, J. P. S. (2013): Human hydatidosis: an under discussed occupational zoonosis in India. Helminthologia. 50 (2): 87 - 90. DOI: 10.2478/s11687-013-0113-7

Snabel, V., Altintas, N., D’amelio, S., NaKao, M., Romig, T., Yolasigmaz, A. et al. (2009): Cystic echinococcosis in Turkey: genetic variability and first record of the pig strain (G7) in the country. Parasitol. Res., 105: 145 - 154. DOI: 10.1007/s00436-009-1376-2

Stefanic, S., Shaikenov, B. S., Deplazes, P., Dinkel, A., Torgerson, P. R., MAthis, A., 2004. Polymerase chain reaction for detection of patent infections of Echinococcus granulosus ("sheep strain") in naturally infected dogs. Parasitol. Res., 92: 347- 351. DOI: 10.1007/s00436003-1043-y

Thienpont, D., Rochette, F., VAnparis,, O. F. J., 1979. Diagnosing helminthiasis by coprological examination. Janssen Research Foundation, Beerse, Belgium, pp 187.

Thompson, R. C. A., Mcmanus, D. P. (2002): Towards a taxonomic revision of the genus Echinococcus. Trends. Parasitol., 18: 452 - 457. DOI: 10.1016/S14714922(02)02358-9

TrAUB, R. J. (2003): Dogs, human and gastrointestinal parasites: Unraveling epidemiological and zoometric relationship in an endemic ten growing community in North east India. Ph. D. dissertation. Murdoch University, Australia

WHO, OIE (2001): WHO/OIE Manual on Echinococcosis in Humans and Animals: a Public Health Problem of Global Concern. Paris, France.

WHO (1996): Report of the third International Symposium on Rabies in Asia. WHO/EMC/ZOO.96.8

WORLD ORganisation FOR ANIMAL HeAlth (OIE) (2008): Chapter 2.1.4. Echinococcosis/Hydatidosis. In: OIE Terrestrial Manual, pp. 175 - 189

Zhang, Y., Bart, J. M., GiraudouX, P., Craig, P., VuitTon, D., Wen, H. (2006): Morphological and molecular characteristics of Echinococcus multilocularis and Echinococcus granulosus mixed infection in a dog from Xinjiang, China. Vet. Parasitol., 139: 244 - 248. DOI: 10.1016/j.vetpar.2006.03.003

ACCEPTED August 28, 2014 